Canadian



Canadian Journal of Civil Engineering Revue canadienne de génie civil

\title{
Evaluation of Dynamic Passing Gap Acceptance on Two- Lane Highways Using Field Data
}

\begin{tabular}{|r|l|}
\hline Journal: & Canadian Journal of Civil Engineering \\
\hline Manuscript ID & cjce-2016-0572.R2 \\
\hline Danuscript Type: & Article \\
\hline $\begin{array}{r}\text { Complete List of Authors: } \\
\text { Is the invited manuscript for } \\
\text { consideration in a Special } \\
\text { Issue? : }\end{array}$ & $\begin{array}{l}\text { Hassein, Udai; Ryerson University, Civil Engineering; Ryerson University, } \\
\text { Civil Engineering } \\
\text { Easa, Said; Ryerson University, Civil Engineering }\end{array}$ \\
\hline Keyword: & Passing Gap Acceptance, Decision Making, Simulink Simulation model \\
\hline & \\
\hline \multicolumn{2}{|c|}{} \\
\hline
\end{tabular}

SCHOLARONE ${ }^{\text {m }}$

Manuscripts 
Canadian Journal of Civil Engineering

\section{Evaluation of Dynamic Passing Gap Acceptance on Two-Lane Highways Using Field Data}

3

4

\author{
Udai Hassein $^{\mathrm{a} *}$, Maksym Diachuk $^{\mathrm{a}}$, and Said Easa ${ }^{\mathrm{a}}$
}

${ }^{a}$ Department of Civil Engineering, Ryerson University, 350 Victoria Street, Toronto, ON, M5B

2K3, Canada

*Corresponding author: uhassein@gmail.com

Word count: 8671 
Canadian Journal of Civil Engineering

\section{ABSTRACT}

29 Gap availability is an important element of safe passing on two-lane highways. Time gaps are

30 used to determine passing behaviour based on human factors. In this paper, the decision whether

31 to accept or reject an available passing gap is modelled using logistic regression technique that

32 included driver characteristics (age and experience) and the gap size. Field studies were

33 conducted to collect experimental data regarding passing driver behaviour. The data were

34 collected using Dual Camera Car DVRs and a GPS data logger device that records the

35 instantaneous speed and position of the three vehicles involved in the passing maneuver: passing

36 vehicle, impeding vehicle, and opposing vehicle. Regression models that include driver age and

37 gender (required as input to the gap acceptance model) were established for initial passing time,

38 starting gap, ending gap, and time to collision. The gap acceptance model was implemented in

39 SIMULINK and the results revealed that driver characteristics significantly affect gap

40 acceptance decisions.

\section{1. Introduction}

43 Adequate passing sight distance (PSD) is necessary to ensure the safety of passing drivers on

44 two-lane highways. The passing maneuver can be completed when there is a safe clearance

45 distance between the passing and incoming vehicles and the driver can safely return to the right

46 lane. When conducting passing maneuvers, there is always a risk of head-on collisions. In

47 Canada, passing (head-on) collisions accounted for approximately $30 \%$ of all collisions reported

48 in 2010 (Rural Road Safety in Canada 2010). In the USA, head-on collisions accounted for

49 approximately $20 \%$ of fatal collisions occurring on rural two-lane highways and passing is one of

50 the primary causes of these types of collisions (Persaud et al. 2004). Passing maneuvers are also 


\section{Canadian Journal of Civil Engineering}

51 regarded as one of the most difficult maneuvers on rural two-lane highways due to the changes in

52 speed and position necessary for safe completion (Mcknight et al. 1970). Therefore, the design of

53 adequate PSD for two-lane highways is critical (Farah 2013).

Despite the importance of this issue, a few studies have attempted to model passing

55 behaviour. Several researchers have developed analytical models that depend on motion

56 equations to ascertain the required sight distances (AASHTO 1994; Polus and Frischer 2000).

57 Some researchers have used macroscopic traffic characteristics to predict the number and

58 frequency of passing maneuvers (Hegeman 2004) while others have focused on the impact of

59 impatience on critical passing gaps (Pollatschek and Polus 2005). Judgment errors regarding

60 distance and speed (of both the passing and opposing vehicles) and insufficient clear sight

61 distance can contribute to passing failure (Clarke et al. 1998). In addition, the variables that

62 influence the mean critical gaps were not accounted for in earlier studies that estimated critical

63 passing gap distributions (Miller and Pretty 1968).

64 There are several issues with the observation of driving behaviour during passing

65 maneuvers. First, the passing maneuvers can occur anywhere along the passing zone. Second,

66 previous field studies do not allow researchers to control the explanatory variables and do not

67 provide information about driver characteristics. Jenkins and Rilett (2004) used driving

68 simulators to collect data and developed a classification system for passing maneuvers, while

69 Bar-Gera and Shinar (2005) used driving simulators to examine the effect of speed differences

70 between passing and impeding vehicles on the driver's desire to pass. However, these studies did

71 not consider opposing vehicles and passing feasibility (such as gap acceptance characteristics).

72 Farah et al. (2009) and Farah (2013) developed a model of passing gap acceptance that considers

73 the impact of traffic conditions, road geometry, and driver characteristics. However, the model 


\section{Canadian Journal of Civil Engineering}

74 was based on driving simulator data and didn't use actual field data. Passing is usually modeled

75 as a binary decision, where the driver either accepts or rejects an available passing gap in the 76 opposing lane.

The purpose of this paper is to examine the effect of driver characteristics on passing maneuvers and to develop a binary model for gap acceptance using field data. Regression models were developed for relevant parameters, including initial passing time, starting gap, ending gap, and time to collision, which are necessary elements of time gap length. The proposed model was

81 implemented in SIMULINK. The following sections describe the data collection and analysis, 82 passing gap acceptance model, and parameter estimation. The simulation and application

83 examples are then presented, followed by a comparison between the results of field studies, 84 computer simulation, and driving simulator.

\section{Data Collection and Analysis}

\section{$87 \quad 2.1$ Variables and Equipment}

88 The elements of the passing maneuver are shown in Fig. 1. The critical point is defined as the

89 point when the passing vehicle is abreast to the impeding vehicle. The starting gap time, $G_{s}(t)$, is

90 defined as the time from the moment a passing vehicle begins to cross the centreline towards the

91 left lane until it reaches the critical point (s). The ending gap time, $G_{e}(t)$, is defined as the time

92 from the moment a passing vehicle moves from the critical point to the start of crossing the

93 centre dashed line and goes back to the right lane (s). The total gap time, $G_{T}(t)$, is defined as the

94 time from the moment the passing vehicle begins to cross the centreline towards the left lane

95 until the moment it begins to cross the centerline and returns to the right lane (s). The transition

96 time, $G_{o}(t)$, is the time from the crossing of the road centerline by the passing vehicle until it 


\section{Canadian Journal of Civil Engineering}

97 completely returns to the right lane. The time to collision, TTC, is defined as the time between

98 the passing and opposing vehicles when the passing vehicle completes the pass and returns to the 99 right lane (s).

100 Using field data, the parameters $G_{s}(t), G_{e}(t), G_{o}(t)$, and $T T C$ were recorded using a 101 smartphone by pressing "Start" and "Lap" when analyzing the data of the video camera for the 102 passing vehicles. A GPS data logger device (Holux RCV-3000) installed on-board the passing, 103 impeding, and opposing vehicles was used to record the position (latitude, longitude, and 104 altitude) and speed of the vehicles at 1-s intervals. The device measures the speed with a 105 precision of $0.1 \mathrm{~m} / \mathrm{s}(0.36 \mathrm{~km} / \mathrm{h})$ (Holux Technology 2014). Since this system is normally 106 applied to passing zones on two-lane highways with speed limits of $80 \mathrm{~km} / \mathrm{h}$, the relative error is 107 expected to be insignificant.

108

109

\subsection{Data Collection Process}

110 Field data were collected at four passing zones on a two-lane highway at three sites: Abu Dhabi 111 and Sharjah in UAE and Muscat in Oman. The lengths of the passing zones ranged from $300 \mathrm{~m}$ 112 to $1200 \mathrm{~m}$. The lane width for each direction was between $3.5 \mathrm{~m}$ and $4 \mathrm{~m}$. All data were collected

113 during off-peak periods on roads with good pavement conditions and good weather. The traffic 114 flow rates ranged from 100 to 250 vehicles/hr. Sites with low flow rates were selected because 115 sites with higher flow rates had limited passing maneuvers, according to research conducted by 116 Harwood et al. (2010). The speed limit on the highway sites was $80 \mathrm{~km} / \mathrm{hr}$. Travel time and 117 speed for each vehicle were recorded using HD in-vehicle video cameras and GPS data loggers. 118 The number of passing maneuvers executed at all passing zones was 105. The sample was 119 randomly selected from each group of passing drivers and included 17 male and 8 female drivers 


\section{Canadian Journal of Civil Engineering}

120 between the ages of 20 and 63 years old. The age mean was 34 and the standard deviation was 12113.

122 The passing scenarios were designed using proper schedules that were given to the 123 drivers of the passing, impeding, and opposing vehicles. The schedule showed the time when the 124 driver should begin driving and was designed to create passing maneuver situations. The

125 impeding driver began driving earlier than the opposing and passing drivers. The driver of the

126 impeding vehicle was instructed to drive slower than the posted speed limit, while the drivers of

127 the passing and opposing vehicles were instructed to drive at the posted speed limit. The 128 individual drivers were unaware that there were two other drivers (with equipped vehicles) on 129 the road to ensure that there was no impact on their behaviour.

130 The actual field data were collected using a total of 25 drivers who repeatedly drove on 131 the highway according to the schedule. However, the situation involving the combination of the 132 passing, impeding, and opposing equipped vehicles occurred only 123 times. There were many 133 instances when the passing driver does not face an impeding equipped vehicle. The information 134 about driver characteristics were collected using a questionnaire completed by each participant 135 before the study commenced.

\section{$137 \quad 2.3$ Variability of PSD Parameters}

138 Table 1 shows the passing maneuver parameters of the field data and their statistical 139 characteristics. The table shows the mean $(\mu)$, standard deviation (SD), and a summary of the 140 statistical measures for all 105 completed passing maneuvers. The passing maneuver parameters 141 are consistent with those obtained in previous research conducted by AASHTO (2004) and 142 Jenkins and Rilett (2005). When analyzing the passing maneuver parameters using AT RISK 


\section{Canadian Journal of Civil Engineering}

143 software (Palisade Corporation 2016), the distribution is generated based on the goodness-of-fit

144 statistics of Chi-Square and Kolmogorov-Smirnov. For each distribution specified, the program

145 tries to find a set of parameters that best fit the observed data. The data for the time of initial 146 maneuver $\left(t_{1}\right)$ followed a normal distribution shape. The data for the time gap length $(\ln G L)$, 147 speed differential $(m)$, and speed of passing vehicle $(V p)$ followed a Weibull distribution.

148 Meanwhile, the data for the initial distance between passing and opposing vehicles $(D)$ followed 149 a lognormal distribution, as shown in Fig. 2.

150 The passing vehicle speed, $V_{p}=23.5 \mathrm{~m} / \mathrm{s}$, suggested by AASHTO (2004), is consistent 151 with the 95th percentile speed of the observed field data. The correlation coefficient between the 152 speed differential $(m)$ and the speed of the passing vehicle, $\rho_{m v}$, was 0.691 . and that between $153 T T C$ and speed reduction, $\rho_{t v}$, was 0.236 . The positive signs of these coefficient are logical since $154 m$ and TTC are expected to increase as the speed of the passing vehicle increases. Information 155 regarding the mean $(\mu)$, standard deviation $(\sigma)$, and probability distribution of various parameters 156 are required for Simulink model and are presented in Table 1. The results for the statistical 157 significance (95\% confidence level) involving the mean of the passing maneuver parameters are 158 also shown in the table.

\section{Passing Gap Acceptance Model}

161 The passing gap acceptance model was estimated using field data to evaluate passing driver 162 behaviour. This study focused on the decision of whether or not to pass a slow moving vehicle. 163 In making this choice, the passing vehicle needs to consider the available passing gaps. The 164 method used in this study is similar to that used by Farah (2013). However, the present study is 165 based on actual driving data instead of driving simulator data. Mathematically, the time gap is 


\section{Canadian Journal of Civil Engineering}

166 calculated by dividing the distance between passing and opposing vehicles by the sum of their

167 speeds.

168 The completion of passing maneuvers regarding the decision of whether to accept or 169 reject an available passing gap is modeled. The logistic regression technique was used to 170 calculate the probability of completing a passing maneuver. The generalized linear model (GLM)

171 is used for this purpose (Kutner et al. 2004; Miles and Shevlin 2001). Let the binary dependent

172 variable (Y) be defined as follows:

$$
Y= \begin{cases}1, & \text { Accepted Gap } \\ 0, & \text { Rejected Gap }\end{cases}
$$

174 where $p\left(Y=1 / X_{i}\right)=\pi$ and $p\left(Y=0 / X_{i}\right)=(1-\pi)$ represent the probabilities of accepted and rejected

175 gaps, respectively, conditional on a vector of the independent variables $X_{i}$. The logistic

176 regression model equation is obtained as follows:

$$
\operatorname{Logit}\left(\frac{\pi}{1-\pi}\right)=\beta_{0}+\beta_{1} X_{1}+\ldots+\beta_{n} X_{n}
$$

where $X_{i}=$ independent variable $i$ and $\beta_{i}=$ coefficient of the independent variable $i$. The coefficients of the logistic regression model can be obtained from the maximum likelihood estimation method using statistical software implements GLM applications (Farah 2016; Kutner et al. 2004). The probability of an acceptable passing gap conditional on a vector of the

182 independent variables $X_{i}, p$ (pass), can be written as follows:

$$
p\left(Y=1 / X_{i}\right)=\frac{\exp \left(\beta_{0}+\beta_{1} X_{1}+\ldots+\beta_{n} X_{n}\right)}{1+\exp \left(\beta_{0}+\beta_{1} X_{1}+\ldots+\beta_{n} X_{n}\right)}
$$

184 The expected probability of a passing gap should be larger than 0.5 (Lobo et al. 2011). The use

185 of Eq. (3), after calibration using field data, allows for estimating the effect of each explanatory 186 variable on the probability that a driver will accept or reject the passing gap. Fig. 3 illustrates the 


\section{Canadian Journal of Civil Engineering}

187 logic of the passing gap acceptance model. The gap acceptance parameters were driver age, 188 driving experience, and gap size. The estimated latent variable was as follows:

$$
G p=-0.632-0.006 \text { Age }+0.008 \operatorname{Exp}+0.560 \ln (G L)
$$

190 where $G p=$ latent variable related to the observed independent variables, $\operatorname{Exp}=$ driving 191 experience of passing driver (years), and $\ln (G L)=$ natural logarithm of gap length (s). The

192 estimated coefficients and goodness of fit for the model were based on the field data collected.

193 The primary factor was gap acceptance, which is consistent with the findings obtained in the 194 majority of previous studies. The results support the hypothesis that drivers make decisions that 195 are dependent on the observed of passing driver characteristics. The results revealed that the 196 estimated model was considerably significant. The model distribution is normal, Pearson Chi197 Square is 9.3, and Log Likelihood is -15.8. The standard error of Age, Exp, and $\ln (P T)$ are 0.005, 198 0.007, and 0.077, respectively. The respective Wald Chi-Square are 1.01, 1.30, and 72.8. The 199 scale is 0.2752 with a standard error of 0.018 .

200 With the latent variable, $G_{p}$, the conditional probability that a driver will perform a 201 passing maneuver (passing gap acceptance, $\mathrm{Y}=1$ ) is determined using Eq. (3) which is larger 202 than 0.5 and consistent with previous research conducted by Lobo et al. (2011). The gap length 203 of Eq. (4) was obtained using the following equation:

$$
G L=t_{1}+G_{s}+G_{e}+G_{o}+T T C
$$

205 where $t_{1}=$ initial passing time (s), Gs = starting gap time (s), Ge = ending gap time (s), and TTC $206=$ time to collision (s). The estimation of these parameters is presented in the following section.

\section{Parameters Estimation}




\section{Canadian Journal of Civil Engineering}

209 Using the collected field data, linear regression models for $t_{l}, G_{s}, G_{e}$, and TTC were developed

210 using SAS software (SAS 2015). The repeated measures ANOVA revealed the significant

211 variables that affect these parameters during different passing maneuvers. Several variable

212 combinations were tried to develop the best regression models. The estimated models for $t_{1}$, Gs,

$213 G e$, and $T T C$ were as follows,

$214 t_{1}=3.810+0.100$ Gender $+0.021 \mathrm{Age}-0.025 \mathrm{Exp}-0.020 \mathrm{Awh}-0.036 \mathrm{~m}$

$215 G_{s}=2.646+1.964$ Gender +0.213 Age $-0.244 \operatorname{Exp}-0.117 \mathrm{Awh}-0.245 \mathrm{~m}$

$216 G_{e}=2.324+1.003$ Gender +0.033 Age $-0.049 \operatorname{Exp}-0.054 \mathrm{Awh}+0.003 \mathrm{df}$

$217 T T C=15.751+0.235$ Gender -0.125 Age $+0.062 \mathrm{Exp}+0.109 \mathrm{Awh}-0.482 \mathrm{~V}_{o}$

218 where Gender = passing driver gender ( 0 for males and 1 for females), Age = passing driver age

219 (years), $\operatorname{Exp}=$ passing driver experience (years), $A w h=$ passing driver weekly driving hours

220 (hrs), $m=$ speed difference $(\mathrm{m} / \mathrm{s}), d f=$ distance headway between the passing and opposing

221 vehicles when the passing vehicle reached the critical point $(\mathrm{m})$, and $V_{o}=$ the opposing vehicle

222 speed $(\mathrm{m} / \mathrm{s})$. The statistical characteristics of the model variables are presented in Table 2.

223 For the initial passing time parameter of Eq. (6), the model considered the initial time of

224 the passing driver to ensure acceptable performance. To obtain precise measurements of this 225 time, field data were collected using different drivers selected from various countries. The initial 226 time was then measured from the moment the driver began to react and initiate the passing 227 maneuver. The mean of the initial time was $3.6 \mathrm{~s}$ and the standard deviation was $0.6 \mathrm{~s} .95 \%$ of 228 the observations were less than $4.5 \mathrm{~s}$. The value $3.6 \mathrm{~s}$ could therefore be used in PSD analysis. There is a reasonable explanation for the choice of the parameters illustrated in the

230 regression models. For $t_{1}, G_{s}$, and $G_{e}$, a positive sign for the gender parameter indicates that 231 female drivers take a longer time than male drivers under similar conditions. A positive sign for 
Canadian Journal of Civil Engineering

232 Age indicates that the gap time will increase with age. A negative sign for Exp and Awh indicates

233 gap time decreases as experience and average weekly hours increase, which is consistent with

234 the results of previous research (Mehmood and Easa 2009). For the TTC model, a negative sign

235 for $V_{o}$ is logical because $T T C$ is expected to increase as the speed of the opposing vehicle

236 decreases, which is consistent with the results of Jenkins and Rilett (2005).

237

238 5. Simulink Implementation

239 Simulink was used in this research because it demonstrated high efficiency of model 240 development. The simulation and model-based design are provided using a block diagram 241 environment that is extremely useful for multi-domain system elaboration. The structure of the 242 Simulink model is shown in Fig. 3.

\section{$244 \quad 5.1$ Model Description}

245 Although the vehicle model allows only two-dimensional (2D) simulation, the results ensure an 246 adequate reflection of the vehicle's maneuvering process. The generalized Simulink-model of 2D

247 vehicle dynamics can be adjusted for any single vehicle including geometric, physical, and 248 design features. The input data from field studies for Gap Length (GL) included the following:

249 (1) passing vehicle's initial speed, (2) initial distance between passing and opposing vehicles, (3)

250 initial acceleration of the opposing vehicle, (4) gender, age, driving experience, and average 251 weekly driving hours of the passing driver, (5) number of lanes, lane width, and distance 252 headway. The Simulink model can randomize the variables of regression models, which are 253 based on probability distributions established from the field data (Table 1 and Fig. 2). This 254 technique was used to provide the sample variability and was accomplished by the addition of 
Canadian Journal of Civil Engineering

255 MATLAB-code to Simulink-model. Thus, the adjusted Simulink model can be used

256 independently for estimating the required gap length $G L$.

\subsection{Vehicle 2D-Dynamics Model}

259 A Simulink model based on 2D vehicle dynamics (steerability) was developed to implement

260 different passing scenarios on a two-lane highway. The basis of a single unit vehicle (SUV)

261 model is the 2D steerability block in which all necessary components are implemented by the

262 Simulink library. Each vehicle is described by a system of ordinary differential equations that are

263 entered in the vehicle universal block, given by

$$
\{\begin{array}{l}
m \delta_{r}\left(\frac{d V_{C x}}{d t}-\frac{d \phi}{d t} V_{C y}\right)=\sum F_{x}^{(e)} \\
m\left(\frac{d V_{C y}}{d t}+\frac{d \phi}{d t} V_{C x}\right)=\sum F_{y}^{(e)} \\
I \frac{d^{2} \phi}{d t^{2}}=\sum M_{Z}
\end{array} \quad\left(\begin{array}{l}
\frac{d V_{C x}}{d t} \\
\frac{d V_{C y}}{d t} \\
\frac{d \omega}{d t}
\end{array}\right)=\left(\begin{array}{ccc}
\frac{1}{m \delta_{r}} & 0 & 0 \\
0 & \frac{1}{m} & 0 \\
0 & 0 & \frac{1}{I}
\end{array}\right)\left(\begin{array}{c}
\sum F_{x}^{(e)} \\
\sum F_{y}^{(e)} \\
\sum M_{C}
\end{array}\right)+\underbrace{\frac{d \phi}{d t}}_{\omega}\left(\begin{array}{c}
V_{C y} \\
-V_{C x} \\
0
\end{array}\right)
$$

265 The primary feature of the proposed SUV model is the four-point road contact (as opposed to

266 the bicycle models that are still widely used). The distribution of vertical forces on wheels

267 (including longitudinal and lateral deviations), which are the most influential factors in the tire

268 slip process, is provided. This distribution accounts for the effect of inertia pseudo-forces in a

269 vehicle's mass center. The model uses a non-linear approximation of tire-road contact depending

270 on the degree of adhesion. The steering axel-angle distribution is represented functionally as a

271 result of the steering trapezoid's design optimization.

272 The system of dynamics equations Eq. (10) is represented by longitudinal, transversal, 273 and rotational dynamics relative to vehicle local coordinate system. $m$ represents the vehicle 


\section{Canadian Journal of Civil Engineering}

274 mass, $I$ represents the moment of inertia relative to axis $\mathrm{OZ}, \mathrm{V}_{\mathrm{Cx}}$ and $\mathrm{V}_{\mathrm{Cy}}$ represent the velocities

275 along the axes of the local coordinate system associated with mass center $\mathrm{C}, \delta_{\mathrm{r}}$ represents the

276 coefficient that takes into account the inertia of the transmission's rotating masses, $\phi$ represents

277 the angle of the vehicle's rotation around axis $\mathrm{OZ}$, and $\mathrm{F}_{\mathrm{x}}^{(\mathrm{e})}, \mathrm{F}^{(\mathrm{e})}{ }_{\mathrm{y}}, \mathrm{M}_{\mathrm{z}}$ signify the generalized

278 external force factors along the $x$ and $y$ axes and around $z$, respectively.

279 The Simulink model can be customized for any vehicle and takes into account the design,

280 physical properties, and geometric properties of the vehicle. The simplest object is shown in Fig.

2814 , which allows for the combination of several car-models in one simulation scenario to reflect

282 overtaking processes on two-lane highways. The basis of a single vehicle model, shown in Fig.

283 4(a), is block 1, where all necessary 2D-steerability components are implemented via the

284 Simulink library. Blocks 2 and 3 are vectors that transmit initial positions (plane location and

285 yaw rotation) and velocities (longitudinal, lateral, and yaw rate) according to degrees of freedom.

286 Block 4 allows for the adjustment of the traction dynamics by means of the desired course

287 velocity, and the current steering wheel angle is provided through input port 5. The outputs of

288 block 1 are as follows: into port 6 - accelerations (longitudinal and lateral) in the vehicle's local

289 coordinate system; into port 7 - velocities (longitudinal and lateral); into port 8 - all absolute

290 displacements relative to the global coordinate system; into port 9 - steering wheel turning

291 angles. Subsystem 10 sets the initial conditions of motion and control laws, and subsystem 11

292 obtains graphical representations of solutions. The model makes it possible to start an animation

293 script that visually reflects the realism of the simulation.

\section{$295 \quad 5.3$ Distance Headway Parameter}




\section{Canadian Journal of Civil Engineering}

296 The PSD length is specified before assigning the location of the three vehicles. The Pitts car-

297 following model can be used to calculate the minimum headway between the passing vehicle and

298 the impeding vehicle (Halati et al. 1997). The minimum distance assumes that the passing

299 vehicle is trying to narrow the distance between the passing and impeding vehicles before

300 initiating a passing maneuver. The following formula was used to calculate the distance headway

301 that is required between the two vehicles:

302

$$
d_{1-2}=L_{i}+10+k V_{p}+b k\left(V_{i}-V_{p}\right)^{2}
$$

303 where $d_{1-2}=$ space headway between the impeding and passing vehicles (from the front bumper

304 to the front bumper), $L_{i}=$ length of the impeding vehicle, and $V_{i}$ and $V_{p}=$ speed of the impeding

305 and passing vehicles, respectively, $b=$ calibration constant that is defined as 0.1 (when $V_{p}>V_{i}$ )

306 or 0 otherwise, and $k=$ driver sensitivity factor for the passing vehicle. In the Pitts car-following

307 model, the default values for the driver sensitivity factor range between $0.6 \mathrm{~s}$ and $1.5 \mathrm{~s}$. At lower

308 values, the behaviour becomes more aggressive and the following vehicles maintain a smaller

309 distance headway. In this paper, the sensitivity for the passing driver can be captured through the

310 variable $k$. The values for $k$ are randomly selected from a uniform distribution, similar to the

311 method used by El Khoury and Hobeika (2012).

\section{$313 \quad 5.4$ Decision Making for Passing Gap Model}

314 Vehicle control depends on the driver's subjective assessment of the road situation, as depicted in

315 Fig. 5. The State-flow chart software provides the steering wheel angle as the output signal $S$.

316 The decisive maneuver is composed of the four simplest combinations, which are executed by

317 state blocks S0, S1, S2, S3, and S4. Therefore, the handling algorithm creates the control signal 


\section{Canadian Journal of Civil Engineering}

$318 \mathrm{~S}$, which is changed functionally according to the current state. Driving modeling was done using

319 the PID-controller, which is well known in automation theory. The PID-controller forms the

320 output control signal from two input signals, which are the desired and actual steering angles.

321 The PID function compensates for the difference between the steering signal input (discussion of

322 gap acceptance) and the current calculated angle of the steering wheel.

323 The actual direction is defined by the current yaw angle phi; and the theoretical direction

324 is calculated as a value of the angle deviation, which is a derivative and described by Hermit

325 polynomials on the basis length $\mathrm{L}$ from initial position $\mathrm{x}_{0}$. The chart operates as follows: When

326 the default initial state S0 is accepted, the zero-output signal S is provided. This corresponds to a

327 straight-ahead movement without any action on the steering wheel. When the input variable

328 decision to accept the passing gap (corresponding to Eq. (1)) becomes logical 1, the transition to

329 state $\mathrm{S} 1$ is carried out. The variable decision is tied with parameter $\pi$ (corresponding to Eq. (2))

330 that estimates the probability of passage using Eq. (3). During the execution of state S1, the

331 passing vehicle is changing locations and moving toward the left lane. The transition from state

332 S1 signifies a switch to state S2 (further rectilinear motion).

333 In this case, the side displacement on the base length L will be completed. State S3 is

334 equivalent to state $\mathrm{S}$, but provides a negative sign for signal $\mathrm{S}$ to return the passing vehicle to

335 the right lane. When a transition from state S2 to state S3 is being executed, the passing vehicle

336 continues in a straight line until the critical point is reached. After that, state S3 provides the

337 signal for the vehicle to return to the right lane. State S4 then provides the signal to continue

338 moving in a straight line. The parameters $\mathrm{t} 1$, Gs, and Ge are used to arrange the conditions of

339 transitions between states. During these time intervals the passing vehicle is changing its

340 transversal position and lane. 


\section{Canadian Journal of Civil Engineering}

341

342

343

344

345

346

347

348

349

350

\subsection{Application of Simulink}

An application example of one loop is provided in this section to illustrate the methodology for distance headway $\left(d_{1-2}\right)$ and gap length $(G L)$ that is used for passenger vehicles. To illustrate the uniqueness of the overtaking conditions and the relative vehicles disposition on rural two-lane highways, for each new simulation before calculations, random realizations of model parameters are generated according to the distributions established from field data. The input field data for the passing vehicle included the following: initial speed of $22.2 \mathrm{~m} / \mathrm{s}$, initial distance of $460.1 \mathrm{~m}$, initial acceleration of the opposing vehicle of $0.51 \mathrm{~m} / \mathrm{s}^{2}$, gender (female $=1$ ), age of 34.8 years, driving experience of 13.9 years and average weekly driving hours of $17.8 \mathrm{hrs}$ for the passing driver, and number of lanes of 2 , lane width of $3.75 \mathrm{~m}$, and design speed of $22.22 \mathrm{~m} / \mathrm{s}$.

Fig. 6 shows the kinematic characteristics of a passing vehicle during an overtaking procedure, allowing for a qualitative assessment of the adequacy of the virtual experiment simulation. The first curve represents the longitudinal acceleration of the vehicle's mass center (Fig. 6(a), blue colour). This curve represents the power unit's ability to realize the traction force depending on the adhesion with the road surface. The results indicate that the passing vehicle accelerates uniformly before transitioning into the opposing lane and shortening the distance to the impending vehicle. The acceleration remains constant after the passing vehicle enters the opposing lane, corresponding to vehicle velocity increments of the value $\Delta v_{p l}$.

The speed increases during overtaking and decreases once the critical point is reached. The lateral acceleration (Fig. 6(a), red colour) best demonstrates the model's ability to represent vehicle dynamics. The absolute value of the lateral acceleration does not exceed $4.5 \mathrm{~m} / \mathrm{s}^{2}$ during the maneuver. The peak values of the lateral acceleration correspond to moments of motion trajectory curvature changes, when lateral reactions reach the highest values. The inertia of 


\section{Canadian Journal of Civil Engineering}

365 model dynamics during the transient process can be seen through the delay of the stabilization 366 mode.

367 The next curve (Fig. 6(b), magenta colour) represents the passing vehicle's displacements 368 on road lanes. Starting offset corresponds to the driver's decision to accept the passing gap, 369 which correlates with the passing gap model. There is then a transition process to the middle of 370 the opposing traffic lane which occurs according to the positive logical value of the parameter

371 decision. Overtaking is done while maintaining a steady position in the opposing lane, and a 372 sharper movement while completing the process and returning to the original lane. The yaw 373 angle curve (Fig. 6(c)) reflects all transition processes and characterizes the driving stability and 374 steerability of the model. The graphics in Fig. 6(a), 6(b), and 6(c) are smooth curves with 375 continuous changes in curvature. This implies a steady motion without any jerking of the vehicle, 376 confirming the quality of the model.

377 Fig. 6(d) illustrates the laws of changes in vehicle velocity during the overtaking process.

378 These speeds are determined by experimentally established average parameters via regression 379 equations with the addition of stochastic components. Fig. 6(e) shows a decrease in the distance 380 between approaching vehicles (from the initial $460.1 \mathrm{~m}$ ). During the simulation, the movement 381 of the impeding, opposing, and passing vehicles is monitored.

\section{6. Comparison of Field, Simulink, and Driving Simulator Results}

384 The substantial variables characterizing the passing maneuver process include passing gap time, 385 following distance, and time to collision. Those variables were observed from the current field 386 study, Simulink model, and the driving simulator study based on Farah (2013). The comparison 


\section{Canadian Journal of Civil Engineering}

387 between the results of the preceding studies is presented in Table 3 . As noted, the values of the 388 passing time gap are slightly different but substantially higher for the field data.

389 There was a slight difference in the gender distributions, where percentage of females in 390 the field and driving simulator data was $32 \%$ and $31 \%$, respectively. The age of the passing 391 driver was slightly higher for the field data, with a mean of 34.4 years compared to a mean of 33 392 years for the driving simulator data. The speeds in the field study were substantially lower than 393 those of the driving simulator study. Table 3 shows a substantial difference in the distributions of 394 m, which was substantially lower in field data compared with driving simulator data.

396 higher with longer passing distances for the driving simulator data. The relative speed between 397 passing and opposing vehicles ( $\mathrm{Vp}-\mathrm{Vo}$ ), start time gap (Gs), end time gap (Ge), and time to 398 collision (TTC) were substantially higher for the field data. The value of Ge was not presented in 399 Farah (2013) but was calculated in this study. Fig. 7 shows a comparison of the estimated 400 parameters of field, Simulink, and driving simulator data for start time gap, end time gap, and 401 time to collision. Note that the field data and Simulink model results are relatively close since the 402 realizations in the Simulink model are generated from the distributions established from the field 403 data.

\section{Conclusions}

406 This paper has presented a modified gap acceptance model for passing maneuvers on two-lane 407 highways using field data. Passing decisions were modeled regarding the decision to accept or 408 reject an available passing gap. The model incorporates variables that capture the effect of driver 


\section{Canadian Journal of Civil Engineering}

409 characteristics, and the attributes of the specific passing gap that are evaluated by the driver.

410 Based on this research, the following comments are offered:

411 1. For the passing time model, regression formulas were developed for initial time, starting gap, 412 ending gap, and time to collision, which are necessary elements of passing maneuvers. The

413 driver factors included gender, age, driving experience, and average weekly driving hours.

414 The models included variables related to the gap itself such as the size of the available 415 passing gap, the speed of the passing, impeding, and opposing vehicles, and the gap between 416 the passing and impeding vehicles. For the gap acceptance model, the gap was formulated 417 using a regression model in which the driver's age and driving experience were found to be $418 \quad$ statistically substantial.

419 2. The models were estimated using data collected in field studies conducted on two-lane 420 highways. Advanced technologies involving in-vehicle video data recording and a GPS data 421 logger were used in data collection. These methods provide improved video image quality 422 and the possibility of determining complete trajectories with increased accuracy. These tools 423 allowed the researchers to obtain data about passing maneuvers with greater efficiency and 424 accuracy.

425 3. A SIMULINK model that implements the proposed gap acceptance framework was 426 presented in this paper. The simulation results were validated for a design speed of $80 \mathrm{~km} / \mathrm{h}$ 427 and revealed comparable statistical values with those of previous studies.

428 4. The comparison of field and driving simulator data showed that the relative distance between 429 passing and opposing vehicles of the driving simulator data was substantially higher. On the 430 other hand, the relative speed between passing and opposing vehicles, start time gap, end 431 time gap, and time to collision were substantially higher for the field data. The results of 


\section{Canadian Journal of Civil Engineering}

432 Simulink model were relatively close to those of the field data, as expected. Field data are

433 recommended for future studies since such data represent driver characteristics in a real life

434 environment. With current advanced technologies, a large amount of data can now be 435 collected in the field with high accuracy.

436 5. This study was based on field data collected on two-lane highways with a speed limit of 80 $437 \mathrm{~km} / \mathrm{h}$. Future research may explore gap acceptance for speeds ranging from 70 to $90 \mathrm{~km} / \mathrm{h}$. In 438 addition, the potential implementation of the presented gap acceptance model for in-vehicle 439 collision warning systems should be explored. Implementation of the presented concept of 440 gap acceptance in left driving systems, such as on Australian highways, should also be 441 explored. It appears that the concept would be applicable as the decision-making process is 442 similar. However, since driver behavior might be different, estimation of relevant parameters $443 \quad$ may be needed.

\section{ACKNOWLEDGEMENTS}

446 The authors are grateful to two anonymous reviewers and the associate editor for their thorough 447 and most helpful comments. This research was supported by the Natural Sciences and 448 Engineering Research Council of Canada (NSERC).

\section{REFERENCES}

451 American Association of State Highway and Transportation Officials. 1994. A Policy on 452 Geometric Design for Highways and Streets. AASHTO, Washington, D. C.

453 American Association of State Highway and Transportation Officials. 2004. A Policy on 454 Geometric Design for Highways and Streets. AASHTO, Washington, D. C. 
Canadian Journal of Civil Engineering

455 Bar-Gera, H., and Shinar, D. 2005. The Tendency of Drivers to Pass Other Vehicles.

Holux Technology Inc., 2014. Holux RCV-3000 GPS Logger User Manual.

473 Jenkins, J. M., and Rilett, L. R. 2004. Application of Distributed Traffic Simulation for Passing 474 Behavior Study. Transportation Research Record, No. 1899, pp. 11-18, Transportation 475 Research Board, Washington, D.C. 
Canadian Journal of Civil Engineering

476 Jenkins, J., Rilett, L. 2005. Classifying passing maneuvers: a behavioral approach.

477 Transportation Research Record, No. 1937, 14-21, Transportation Research Board, $478 \quad$ Washington, D.C., USA.

479 Kutner, M. H., Nachtsheim, C., and Neter, J. 2004. Applied linear regression models. McGraw$480 \quad$ Hill/Irwin.

481 Lobo, A., Jacques, M., Rodrigues, C., Couto, A. 2011. "Free Gap" Evaluation for Two-Lane 482 Rural Highways. Transportation Research Board Annual Meeting, Washington, D.C., $483 \quad$ USA.

484 McKnight, J., Adams, B.B.1970. "Driver education task analysis, Task Descriptions," 485 Human Resources Research Organization (HumPRO), vol. 1, Alexandria. http://www.civil.uwaterloo.ca/saccomanno/Publications/trbpaper \%2001-2346.doc

487 Mehmood, A., and Easa, S. M. 2009. Modeling reaction time in car-following behavior based on human factors. International Journal of Applied Science, Engineering and Technology, $5(2), 93-101$.

490 Miller, A. J., and Pretty, R. L. 1968. Overtaking on Two-Lane Rural Roads. Proc., 4th Australian 491 Road Research Board Conference, Vol. 4, Part 1.

492 Miles, J., and Shevlin, M. 2001. Applying regression and correlation: A guide for students and 493 researchers. Sage.

494 Palisade Corporation 2016. @RISK User Guide. Retrieved from 495 https://www.palisade.com/downloads/manuals/6/EN/PTree6_EN.pdf

496 Persaud, B.N., Retting, R.A., Lyon, C.A. 2004. "Crash reduction following installation of 497 centerline rumble strips on rural two-lane roads.” Accident Analysis and Prevention, 36 $498 \quad$ (6) 1073-1079. 
Canadian Journal of Civil Engineering

499 Pollatschek, M. A., and Polus, A. 2005. Modeling Impatience of Drivers in Passing Maneuvers.

500 In Transportation and Traffic Theory: Flow, Dynamics and Human Interaction (H. S.

501 Mahmassani, ed.), Emerald Group Publishing, Bingley, pp. 267-279, UK.

502 Polus, A., Livneh, M., and Frischer, B. 2000. Evaluation of the Passing Process on Two-Lane

503 Rural Highways. In Transportation Research Record: Journal of the Transportation

$504 \quad$ Research

505 Board, No. 1701, TRB, National Research Council, pp. 53-60, Washington, D.C.

506 Rural Road Safety in Canada 2010. Traffic Collision Trends and Recommended Strategies.

507 Ottawa, Canada.

508 SAS (2015). SAS: Enterprise Guide. Retrieved from

509 http://www.sas.com/technologies/bi/query_reporting/guide/ 


\section{Canadian Journal of Civil Engineering}

\section{LIST OF FIGURES}

512 Figure 1. Elements of the passing maneuver

513 Figure 2. Frequency distributions of observed passing maneuver field data: (a) gap length (ln(GL)); (b) Initial distance; (c) Speed differential (m); and (d) Passing vehicle speed $(\mathrm{Vp})$

516 Figure 3. Logic of the Simulink model

517 Figure 4. Simulink model of plane single unit vehicle (SUV) dynamics

518 Figure 5. State-flow chart of maneuver arrangement by steering control

519 Figure 6. Simulation output: (a) passing vehicle acceleration during overtaking, (b) passing vehicle lateral displacement, (c) passing vehicle yaw turning, (d) vehicle longitudinal velocity, (e) distance between passing and opposing vehicles

522 Figure 7. Comparison of the estimated parameters of field, Simulink, and driving simulator: (a) start time gap, (b) end time gap, (c) time to collision. 


\section{Canadian Journal of Civil Engineering}

526

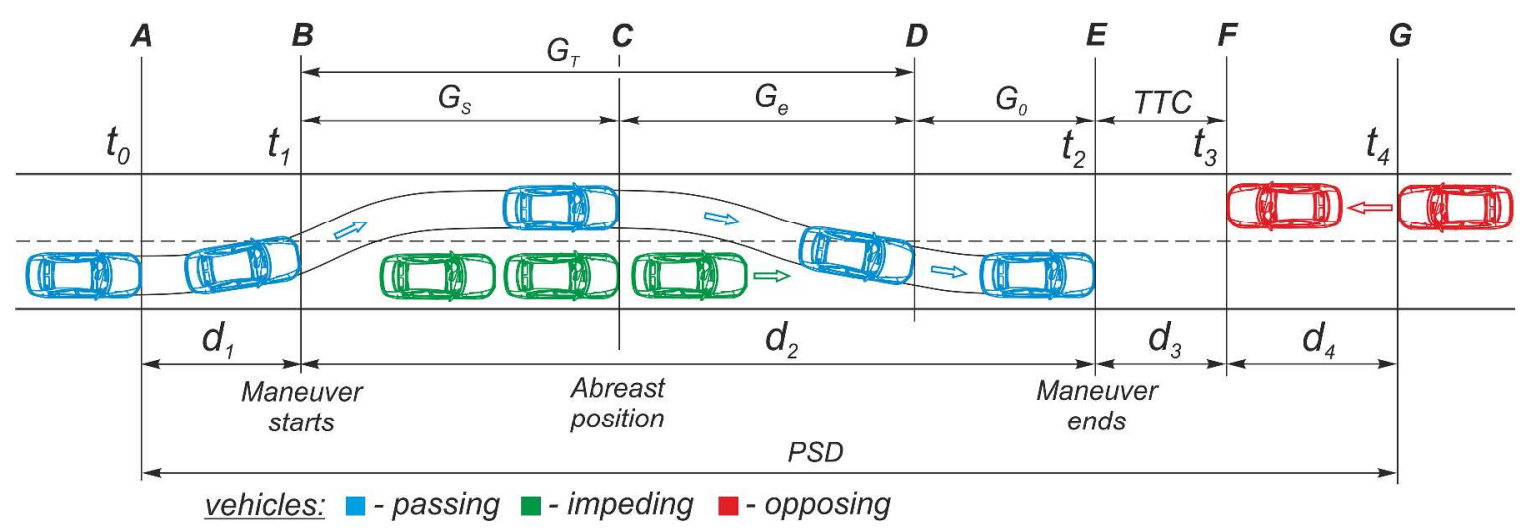

Figure 1 Elements of the passing maneuver 


\section{Canadian Journal of Civil Engineering}

529
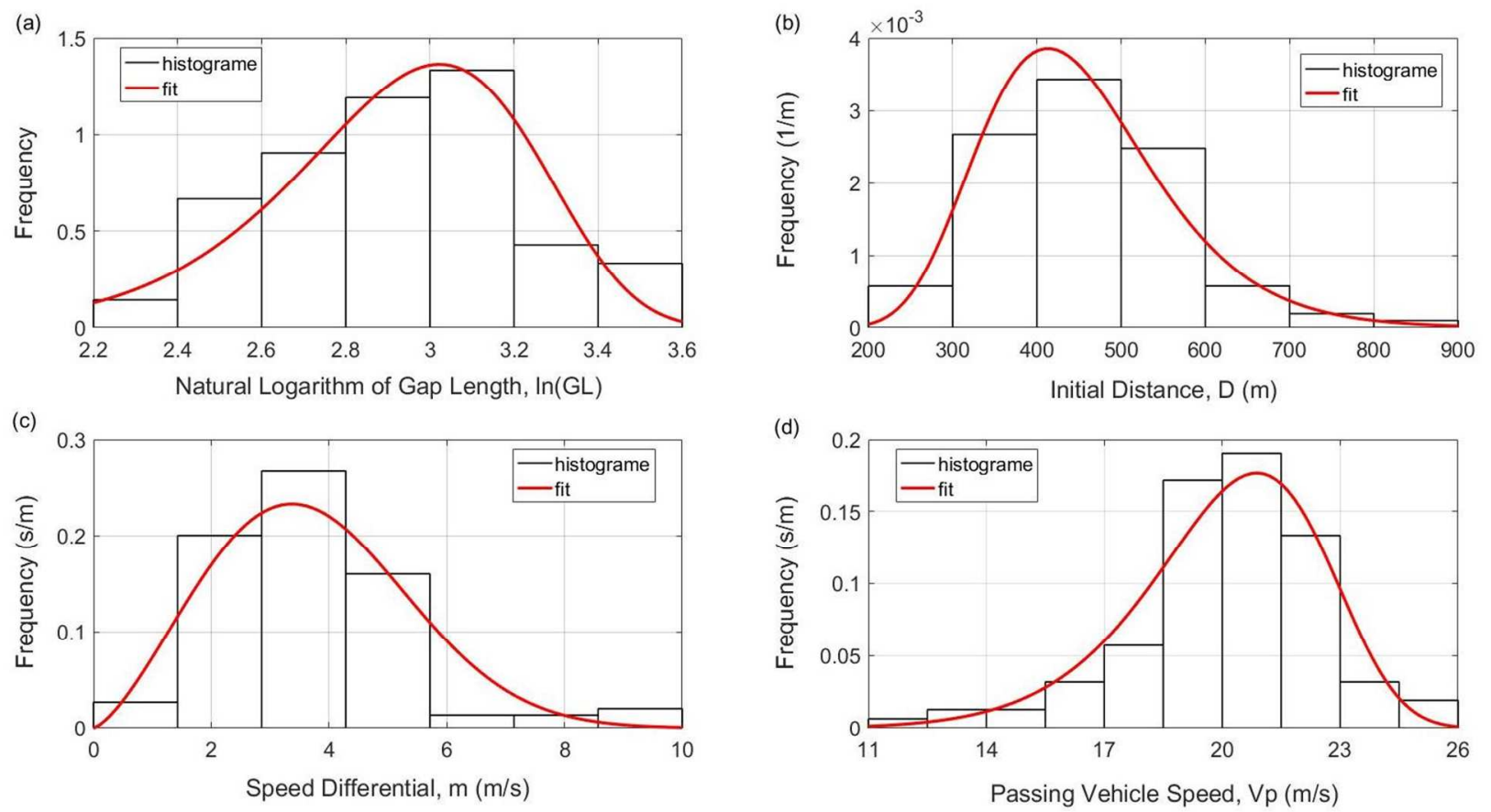

Figure 2 Frequency distributions of observed passing maneuver from field data: (a) Gap length 533

$(\ln (\mathrm{GL}))$, (b) Initial distance, (c) Speed differential, and (d) Passing vehicle speed (Vp) 


\section{Canadian Journal of Civil Engineering}



Figure 3 Logic of the Simulink model 


\section{Canadian Journal of Civil Engineering}

541

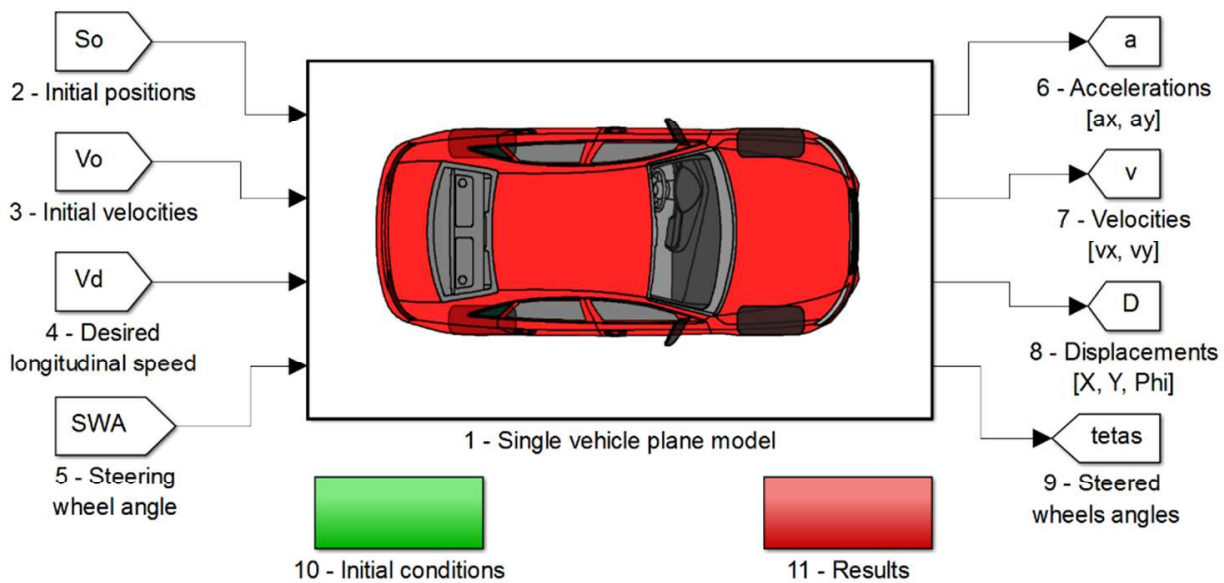

Figure 4 Simulink model of plane single unit vehicle (SUV) dynamics 
Canadian Journal of Civil Engineering

545

546

MATLAB Function
ang $=\mathrm{t}(\mathrm{L}, \mathrm{xO}, \mathrm{x} 1, \mathrm{H})$

Simulink Function

$s=\operatorname{pidst}($ Ang, phi)

So
en: $S=0 ;$

[G_accept==1 \& $\operatorname{after}(\mathrm{t} 1-1.5, \mathrm{sec})]$

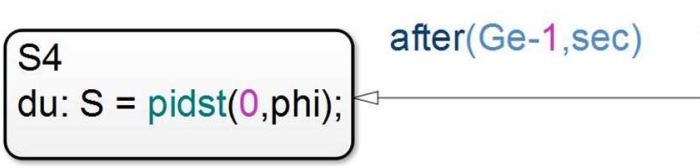

S3

en: $L=v x^{*}(\mathrm{Ge}-1)$ $\mathrm{xo}=\mathrm{x} 1$;

$d u$ : Ang = tl(L,xo, $x 1,3.6)$; $\mathrm{S}=$ pidst(-Ang,phi);

$$
\begin{aligned}
& \text { S1 } \\
& \text { en: } L=v x^{*}(G s / 2) \\
& x o=x 1 \\
& \text { du: } \text { Ang = tl(L,xo,x1,3.0); } \\
& \quad \text { S = pidst(Ang,phi); }
\end{aligned}
$$

S2

du: $S=\operatorname{pidst}(0$, phi $)$;

Figure 5 State-flow chart of maneuver arrangement by steering control 


\section{Canadian Journal of Civil Engineering}

(a)
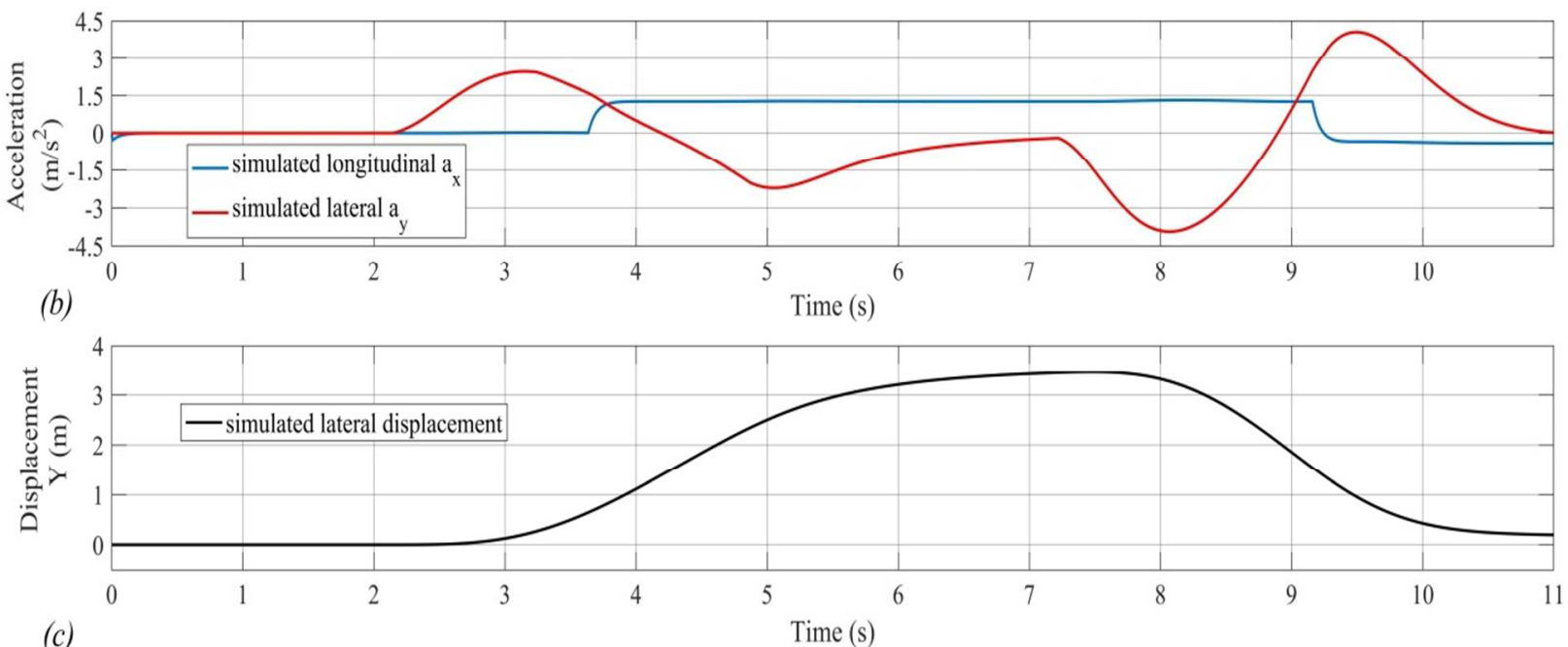

(c)

Time (s)



(d)
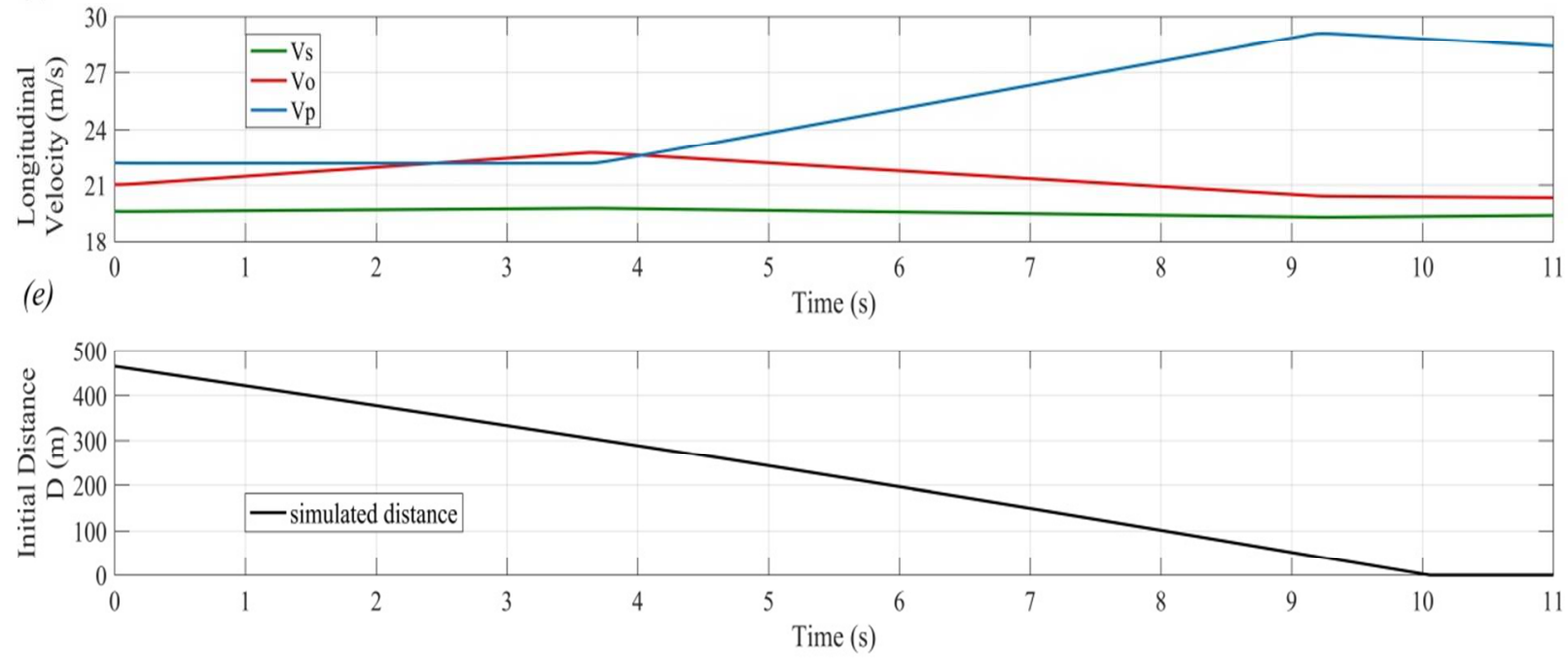

Figure 6 Simulation output: (a) Passing vehicle acceleration during overtaking, (b) Passing vehicle lateral displacement, (c) Passing vehicle yaw turning, (d) Vehicle longitudinal velocity,

(e) Distance between passing and opposing vehicles 
Canadian Journal of Civil Engineering

(a)

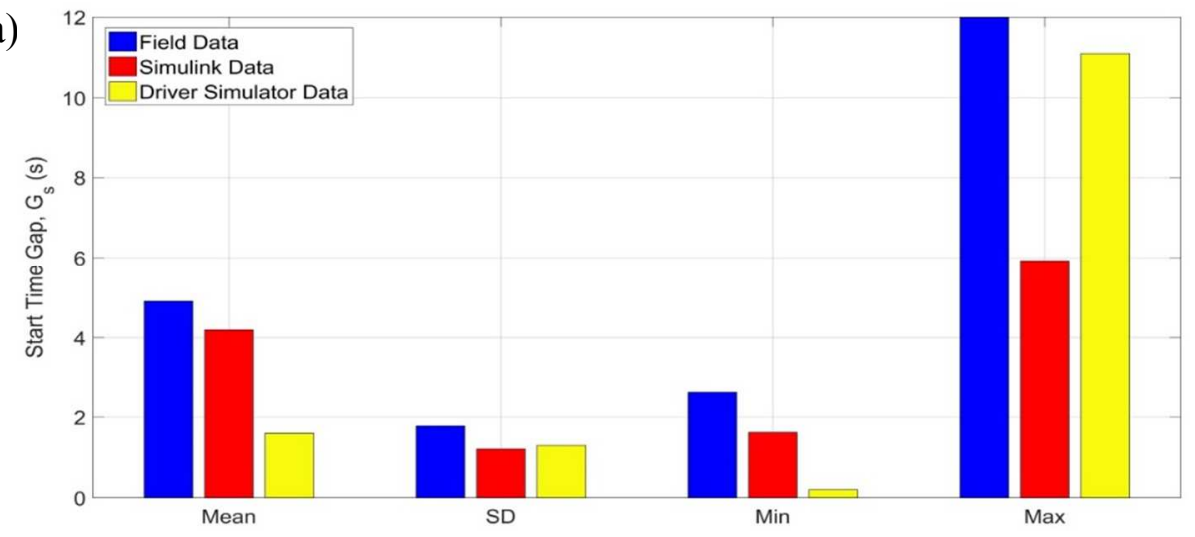

(b)

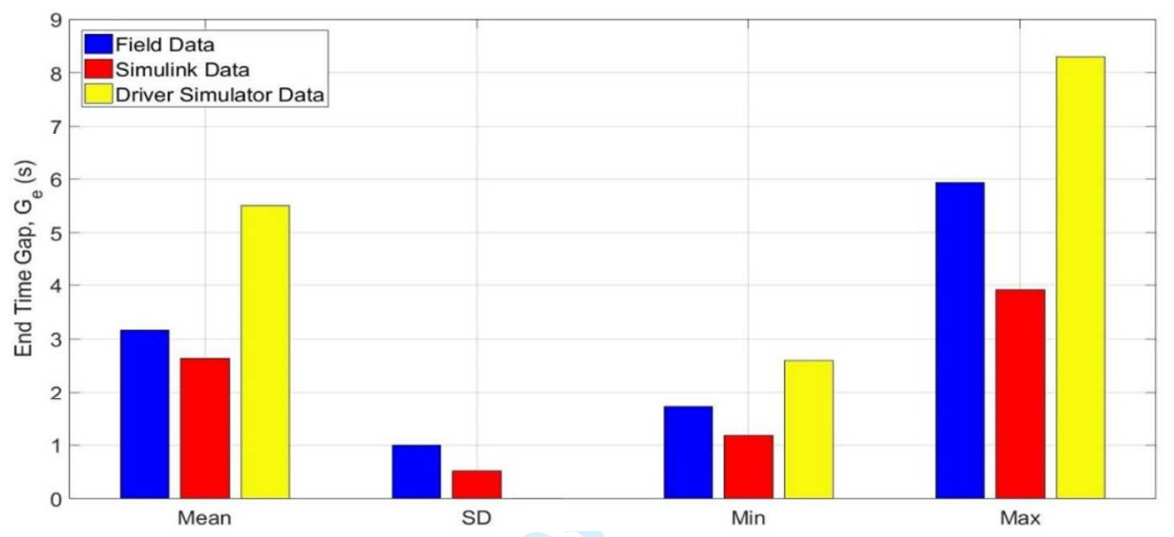

(c)



Figure 7 Comparison of the estimated parameters of field, Simulink, and driving simulator output: (a) Start time gap, (b) End time gap, (c) Time to collision 
Canadian Journal of Civil Engineering

\section{LIST OF TABLES}

563 Table 1 Results of passing maneuver parameters of field study and their statistical characteristics

564 Table 2 Statistical results of estimated passing parameters

565 Table 3 Comparison of the estimated parameters of field studies, Simulink, and driving simulator 566

567

568 


\section{Canadian Journal of Civil Engineering}

569

570

Table 1. Results of passing maneuver parameters of field study and their statistical

\begin{tabular}{ccccccccccc}
\hline Variable $^{\text {b }}$ & Dist. & Mean & SD & DF & t-value & P-value & Chi-Sq & K-S & 95th \% & 99th \% \\
\hline $\mathrm{Vp}(\mathrm{m} / \mathrm{s})$ & Weibull & 20.10 & 2.39 & 484 & 20.10 & 0.16 & 13.29 & 0.10 & 23.52 & 24.79 \\
$\mathrm{Vi}(\mathrm{m} / \mathrm{s})$ & Weibull & 16.37 & 1.94 & 440 & 16.37 & 0.03 & 18.31 & 0.12 & 18.96 & 20.33 \\
$\mathrm{Vo}(\mathrm{m} / \mathrm{s})$ & Weibull & 17.23 & 4.98 & 638 & 17.23 & 0.00 & 40.49 & 0.15 & 22.23 & 23.39 \\
$\mathrm{~m} \mathrm{(m/s)}$ & Weibull & 3.73 & 1.64 & 405 & 3.40 & 0.21 & 12.14 & 0.09 & 6.68 & 9.21 \\
$\mathrm{Acc}\left(\mathrm{m} / \mathrm{s}^{2}\right)$ & Lognorm & 0.61 & 0.30 & 49 & 0.61 & 0.09 & 15.57 & 0.12 & 1.21 & 1.52 \\
$\mathrm{Dec}\left(\mathrm{m} / \mathrm{s}^{2}\right)$ & Lognorm & 0.27 & 0.30 & 51 & -0.27 & 0.00 & 26.77 & 0.12 & 0.09 & 0.23 \\
$\mathrm{t} 1(\mathrm{~s})$ & Lognorm & 3.57 & 0.63 & 205 & 3.57 & 0.00 & 183.00 & 0.15 & 4.50 & 5.00 \\
$\mathrm{t} 2(\mathrm{~s})$ & Lognorm & 9.60 & 2.45 & 457 & 4.99 & 0.21 & 11.69 & 0.09 & 14.58 & 15.75 \\
$\mathrm{Gs}(\mathrm{s})$ & Lognorm & 4.90 & 1.78 & 368 & 2.83 & 0.01 & 20.83 & 0.12 & 8.94 & 11.91 \\
$\mathrm{Ge}(\mathrm{s})$ & Lognorm & 3.16 & 1.00 & 278 & 2.06 & 0.18 & 12.14 & 0.05 & 5.38 & 5.86 \\
$\mathrm{TTC}(\mathrm{s})$ & Weibull & 6.11 & 4.66 & 581 & - & 0.00 & 19.68 & 0.67 & 15.69 & 17.54 \\
\hline
\end{tabular}

571

572

573

574

575

576

577

578

579

580

581

\section{characteristics $^{\mathrm{a}}$}

${ }^{\text {a }}$ DF: degree of freedom; Dist: Distribution; Chi-Sq: Chi-Square Statistic; K-S: Kolmogorov-Smirnov statistic; TTc alpha: 1.1674; TTc beta: 6.0788 .

${ }^{\mathrm{b}} \mathrm{Vp}=$ passing vehicle speed $(\mathrm{m} / \mathrm{s}) ;{ }^{\mathrm{b}} \mathrm{Vi}=$ impeding vehicle speed $(\mathrm{m} / \mathrm{s}) ;{ }^{\mathrm{b}} \mathrm{m}=$ speed difference $(\mathrm{m} / \mathrm{s}) ;{ }^{\mathrm{b}}$ Acc $=$ passing vehicle acceleration $\left(\mathrm{m} / \mathrm{s}^{2}\right) ;{ }^{\mathrm{f}}$ Dec $=$ passing vehicle deceleration $\left(\mathrm{m} / \mathrm{s}^{2}\right) ;{ }^{\mathrm{g}} \mathrm{t}_{1}=$ initial passing time $(\mathrm{s}) ;{ }^{\mathrm{h}} \mathrm{t}_{2}=$ passing time (s); ${ }^{\mathrm{b}} \mathrm{Gs}=\operatorname{starting}$ gap $(\mathrm{s}) ;{ }^{\mathrm{b}} \mathrm{Ge}=\operatorname{ending}$ gap $(\mathrm{s}) ;{ }^{\mathrm{b}} \mathrm{TTC}=$ time to collision (s). 
Canadian Journal of Civil Engineering

\begin{tabular}{|c|c|c|c|c|}
\hline Variables & Coefficient & Standard error & t-value & p-value \\
\hline \multicolumn{5}{|c|}{ (a) Initial Passing Time (t1) } \\
\hline Constant & 3.810 & 0.353 & 10.79 & $<.0001$ \\
\hline Gender & 0.100 & 0.174 & -0.58 & 0.57 \\
\hline Age (year) & 0.021 & 0.018 & 1.14 & 0.26 \\
\hline Exp (year) & -0.025 & 0.021 & -1.23 & 0.22 \\
\hline Awh (h) & -0.020 & 0.011 & -1.88 & 0.06 \\
\hline $\mathrm{m}(\mathrm{m} / \mathrm{s})$ & -0.036 & 0.043 & -0.84 & 0.41 \\
\hline Model Root MSE & 0.592 & & & \\
\hline Model F-Value & 4.06 & & & \\
\hline \multicolumn{5}{|c|}{ (b) Start Time Gap Time (Gs) } \\
\hline Constant & 2.646 & 0.874 & 3.03 & 0.00 \\
\hline Genter & 1.964 & 0.430 & 4.57 & $<.0001$ \\
\hline Age (year) & 0.213 & 0.045 & 4.72 & $<.0001$ \\
\hline Exp (year) & -0.244 & 0.051 & -4.81 & $<.0001$ \\
\hline Awh (h) & -0.117 & 0.027 & -4.40 & $<.0001$ \\
\hline $\mathrm{m}(\mathrm{m} / \mathrm{s})$ & -0.245 & 0.105 & -2.33 & 0.02 \\
\hline Model Root MSE & 1.463 & & & \\
\hline Model F-Value & 10.86 & & & \\
\hline \multicolumn{5}{|c|}{ (c) End Time Gap (Ge) } \\
\hline Constant & 2.324 & 0.481 & 4.83 & $<.0001$ \\
\hline Genter & 1.003 & 0.229 & 4.38 & $<.0001$ \\
\hline Age (year) & 0.033 & 0.023 & 1.41 & 0.16 \\
\hline Exp (year) & -0.049 & 0.027 & -1.87 & 0.06 \\
\hline Awh (h) & -0.054 & 0.014 & -3.89 & 0.00 \\
\hline $\mathrm{df}(\mathrm{m})$ & 0.003 & 0.001 & 4.72 & $<.0001$ \\
\hline Model Root MSE & 0.769 & & & \\
\hline Model F-Value & 15.39 & & & \\
\hline \multicolumn{5}{|c|}{ (d) Time to Collision (TTC) } \\
\hline Constant & 15.751 & 2.941 & 5.36 & $<.0001$ \\
\hline Genter & 0.236 & 1.181 & -0.20 & 0.84 \\
\hline Age (year) & -0.125 & 0.121 & -1.03 & 0.30 \\
\hline Exp (year) & 0.062 & 0.138 & 0.45 & 0.66 \\
\hline Awh (h) & 0.109 & 0.071 & 1.53 & 0.13 \\
\hline $\operatorname{Vo}(\mathrm{m} / \mathrm{s})$ & -0.482 & 0.082 & -5.92 & $<.0001$ \\
\hline Model Root MSE & 3.984 & & & \\
\hline Model F-Value & 8.7 & & & \\
\hline
\end{tabular}


Canadian Journal of Civil Engineering

585 Table 3. Comparison of the estimated parameters of field, Simulink, and driving simulator data 586

\begin{tabular}{|c|c|c|c|c|c|c|}
\hline \multirow{2}{*}{$\begin{array}{l}\text { Sample } \\
\text { Variable }\end{array}$} & \multicolumn{2}{|c|}{$\begin{array}{l}\text { Field } \\
\text { Data }\end{array}$} & \multicolumn{2}{|c|}{$\begin{array}{l}\text { Simulink } \\
\text { Data }\end{array}$} & \multicolumn{2}{|c|}{$\begin{array}{r}\text { Driver Simulat } 587 \\
\text { Data } \quad 588 \\
\end{array}$} \\
\hline & Mean & SD & Mean & SD & Mean & $\begin{array}{l}589 \\
\text { Sß90 }\end{array}$ \\
\hline GT (s) & 8.06 & 2.33 & 6.82 & 1.57 & 7.10 & 2.5491 \\
\hline GD (m) & 161.01 & 45.81 & 167.0 & 44.15 & 175.50 & $\begin{array}{r}56.583 \\
594\end{array}$ \\
\hline $\mathrm{Vp}(\mathrm{km} / \mathrm{h})$ & 72.36 & 8.61 & 83.94 & 8.79 & 75.60 & 21.205 \\
\hline $\mathrm{d} 12(\mathrm{~m})$ & 52.49 & 17.09 & 36.91 & 5.49 & 13.50 & 10.3907 \\
\hline $\mathrm{Vi}(\mathrm{km} / \mathrm{h})$ & 58.91 & 6.97 & 59.27 & 8.18 & 60.50 & $\begin{array}{r}598 \\
-599\end{array}$ \\
\hline $\mathrm{m}(\mathrm{km} / \mathrm{h})$ & 13.44 & 5.89 & 12.76 & 4.63 & 15.10 & $\begin{array}{r}13.600 \\
601\end{array}$ \\
\hline $\mathrm{D}(\mathrm{m})$ & 451.25 & 109.45 & 500.7 & 70.18 & 480.40 & 203602 \\
\hline $\begin{array}{l}\mathrm{Vp}-\mathrm{Vo} \\
(\mathrm{km} / \mathrm{h})\end{array}$ & 10.32 & 10.82 & 12.50 & 11.03 & 0.30 & $\begin{array}{r}603 \\
8.2604 \\
605\end{array}$ \\
\hline Gs (s) & 4.90 & 1.78 & 4.19 & 1.21 & 1.60 & 1.3006 \\
\hline $\mathrm{Ge}(\mathrm{s})$ & 3.16 & 1.00 & 2.63 & 0.517 & 5.50 & $\begin{array}{l}001 \\
-608\end{array}$ \\
\hline TTC (s) & 6.11 & 4.66 & 5.57 & 1.31 & 3.90 & 4. 6099 \\
\hline
\end{tabular}

611

$612{ }^{\mathrm{a}} \mathrm{GD}=$ gap distance corresponding to $\mathrm{GT}$ and $\mathrm{D}=$ Initial distance between passing and

613 opposing vehicles, and $\mathrm{Vp}-\mathrm{Vo}=$ relative speed.

614

615

616

617 